\title{
駆動源に飽和を有する移動ロボットの フォーメーション制御*
}

市原 裕之十・中野 晃平 ${ }^{\dagger}$

\author{
Formation Control for Mobile Robots with Saturated Driving*
}

\author{
Hiroyuki ICHIHARA ${ }^{\dagger}$ and Kohei NAKANO ${ }^{\dagger}$
}

\begin{abstract}
This paper deals with formation control of mobile robots whose actuators are saturated. Each mobile robot has two independent wheels that are driven by their rotational speeds as control input. Each mobile robot also has a virtual vehicle and consensus of all of the virtual vehicles enables us to achieve formation of the mobile robots. If each mobile robot has saturation on their rotational speeds of the wheels, standard consensus protocols cannot achieve formation of the mobile robots as well as consensus of the virtual vehicles. To cope with this issue, this paper discusses a time-varying gain in the consensus protocol that is introduced so as not to saturate the rotational speeds. This paper also proposes a design method of the time-varying gains which are not common for the mobile robots and are able to improve the convergence speed of formation. The paper finally shows an experiment of formation control with hand made mobile robots as well as numerical examples.
\end{abstract}

\section{1.はじめに}

マルチエージェントシステムでは, 複数のエージェン トが通信やセンシングによって互いの状態を交換し, シ ステム全体のレベルで共通の目的を達成する。 とくに， 各エージェントが任意の初期状態から漸近的に状態を一 致させることを合意を得るという，また，合意を得るた めの入力を設計する問題を合意問題という $[1-3]$. 合意 制御では，それぞれのエージェントに事前に合意值を参 照值として与えるのではなく，自律的かつ動的に合意值 を定める情報交換のためのプロトコルが制御則として標 準的に用いられる。マルチエージェントシステムの合意 問題において入力飽和を考慮する場合，エージェント間 の通信形態を表す固定されたグラフ構造 [4] が全域木を 含むとき，標準的なプロトコルで合意を得ることができ る [5]. また, 無向グラフのとき, 線形行列不等式を用い たスケーラブルな設計条件が提案されている $[6]$.

一方で, 各エージェントが非ホロノミック特性を有す

* 原稿受付 2017 年 1 月 5 日

第 60 回システム制御情報学会研究発表講演会において一 部を発表 (2016 年 5 月)

†明治大学 理工学部 Faculty of Science and Engineering,

Meiji University; 1-1-1 Higashimita, Tama, Kawasaki, Kanagawa 214-8571, JAPAN

Key Words: multi-agent system, consensus, input saturation.
る移動ロボットに対しては, 移動ロボットの位置から距 離をもたせた固定点に関して動特性を線形化する入力を 施し，固定点の動特性を仮想ビークルと考える。ささらに， 仮想構造を用いて仮想ビークルの合意を得ることで, 移 動ロボットのフォーメーション形成が可能となる $[7,8]$. しかし, 仮想ビークルの合意に高い速応性を要求する場 合, グラフ構造にかかわらず, 仮想ビークルの位置や姿 勢角に関して標準的なプロトコルで必ずしも合意を得ら れるとは限らない，つまり，車輪を駆動するための入力， すなわち実入力に対する飽和を考慮して合意プロトコル を設計する必要がある [9]. これは, 線形化入力に対する 飽和を考えることとは本質的に異なる。

本論文では, 標準的な合意プロトコルで用いる定数ゲ インを時変とし, 実入力が飽和に達しないようにゲイン を変化させることで, 移動ロボットのフォーメーション 形成が可能であることを示す．既発表の結果 [9] に加え 本論文では, 時変ゲインを定数ゲインと時変ゲインに分 けて設計しなおすことで，実入力の飽和を防ぎつつより 高い速応性が実現できることを示す．また，数值計算に 加え, 実機によるフォーメーション制御実験を通して提 案した合意プロトコルの効果を検証する.

本論文では以下の記号を用いる， $\mathbb{R}$ を実数の集合， $\mathbb{R}^{n}$ を $n$ 次実べクトルの集合, $\mathbb{R}^{n \times m}$ を $n \times m$ 実行列の集合 とする。また， $\mathbf{0}_{N}, \mathbf{1}_{N} \in \mathbb{R}^{N}$ をそれぞれ要素がすべて 0 
および1のベクトル，凤はクロネッカ積とする，さらに， $z_{i} \in \mathbb{R}$ に対し，飽和を表す関数をつぎのように定義する。

$$
\sigma\left(z_{i}\right)= \begin{cases}\bar{z}_{i}, & \text { if } z_{i}>\bar{z}_{i} \\ z_{i}, & \text { if }-\bar{z}_{i} \leq z_{i} \leq \bar{z}_{i} \\ -\bar{z}_{i}, & \text { if } z_{i}<-\bar{z}_{i}\end{cases}
$$

ここで， $\bar{z}_{i}$ は正の定数とする. $z \in \mathbb{R}^{m}$ に対しては, $\Phi(z)=\left[\sigma\left(z_{1}\right), \ldots, \sigma\left(z_{m}\right)\right]^{\top}$ とする. グラフ $\mathcal{G}=\mathcal{G}(\mathcal{V}, \mathcal{E})$ は，頂点集合 $\mathcal{V}=\{1,2, \ldots, n\}$ 拈よび辺集合 $\mathcal{E} \subseteq \mathcal{V} \times \mathcal{V}$ か らなる. $\mathcal{N}_{i}$ は頂点 $i \in \mathcal{V}$ の隣接集合を表す. $\mathcal{A}_{d} \in \mathbb{R}^{n \times n}$ を隣接行列, $\mathcal{D} \in \mathbb{R}^{n \times n}$ を次数行列とするとき, $\mathcal{G}$ に対 応するグラフラプラシアンは $\mathcal{L}(\mathcal{G})=\mathcal{D}-\mathcal{A}_{d}$ である.

\section{2. 問題設定}

$i$ 番目の移動ロボットの状態方程式をつぎのように 表す.

$$
\left[\begin{array}{c}
\dot{r}_{i, x}^{o}(t) \\
\dot{r}_{i, y}^{o}(t) \\
\dot{\theta}_{i}(t)
\end{array}\right]=\left[\begin{array}{cc}
\cos \theta_{i}(t) & 0 \\
\sin \theta_{i}(t) & 0 \\
0 & 1
\end{array}\right]\left[\begin{array}{c}
v_{i}(t) \\
w_{i}(t)
\end{array}\right]
$$

ここで, $\left(r_{i, x}^{o}, r_{i, y}^{o}\right)$ は移動ロボットの位置, $\theta_{i}(t)$ は姿勢 角， $v_{i}(t)$ は並進速度， $w_{i}(t)$ は角速度である。 $v_{i}(t)$ 打よ び $w_{i}(t)$ は, 移動ロボットの左右の車輪の角速度 $\omega_{i, L}(t)$ および $\omega_{i, R}(t)$ とつぎの関係がある。

$$
\left[\begin{array}{c}
v_{i}(t) \\
w_{i}(t)
\end{array}\right]=G_{i} \Phi\left(\omega_{i}(t)\right)
$$

ただし, $\omega_{i}(t)=\left[\omega_{i, R}(t) \omega_{i, L}(t)\right]^{\top}, \bar{\omega}_{i, L}=\bar{\omega}_{i, R}=\bar{\omega}$,

$$
G_{i}=\left[\begin{array}{cc}
\frac{R_{i}}{2} & \frac{R_{i}}{2} \\
\frac{R_{i}}{T_{i}} & -\frac{R_{i}}{T_{i}}
\end{array}\right]
$$

とする. $R_{i}$ は車輪の半径, $T_{i}$ は車輪間隔であり, $\operatorname{det} G_{i}=$ $-R_{i}^{2} / T_{i} \neq 0$ である. (2) 式は, 移動ロボットの駆動源で ある左右の車輪への角速度入力に飽和があることを表し ている。 (1), (2) 式と同じ動特性を有する $N$ 台の移動口 ボットが互いの位置情報を交換するときの通信形態を表 すグラフを $\mathcal{G}$ とする． $\mathcal{L}(\mathcal{G}) \in \mathbb{R}^{N \times N}$ に対して，つぎの 仮定を扮く。

（仮定 1） $\mathcal{G}$ は無向グラフとする.

(仮定 2) $\mathcal{L}(\mathcal{G})$ の零固有值は単純である.

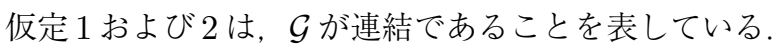

\section{1 仮想構造の導入}

$i$ 番目の移動ロボットの位置 $\left(r_{i, x}^{o}, r_{i, y}^{o}\right)$ に対して $\left(r_{i, x}, r_{i, y}\right)$ を位置とする仮想ビークル [7](Virtual Vehicle, VV) を Fig.1のように設定する。ただし，移動口 ボットと対応する仮想ビークルの姿勢角は同一とする， $i$ 番目の移動ロボットと対応する仮想ビークルの位置関係 はつぎのと抢りである。

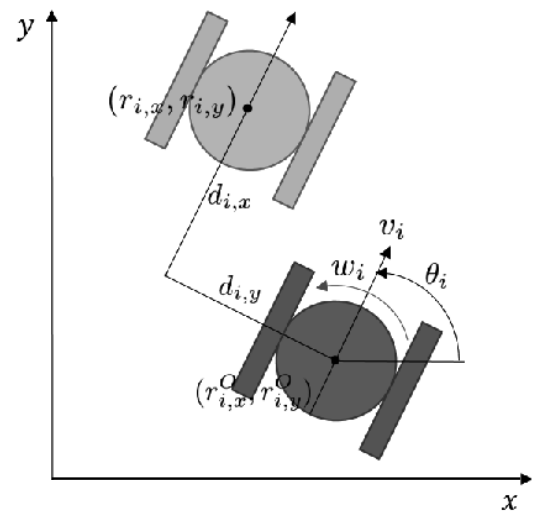

Fig. 1 Virtual vehicle

$$
r_{i}(t)=\left[\begin{array}{c}
r_{i, x}^{o}(t)+d_{i, x} \cos \theta_{i}(t)-d_{i, y} \sin \theta_{i}(t) \\
r_{i, y}^{o}(t)+d_{i, x} \sin \theta_{i}(t)+d_{i, y} \cos \theta_{i}(t)
\end{array}\right]
$$

ただし， $r_{i}(t)=\left[r_{i, x}(t) r_{i, y}(t)\right]^{\top}$ とする. (3) 式の両辺を 時間微分し, (1), (2) 式を考慮することで, $i$ 番目の移動 ロボットに対応する仮想ビークルの状態方程式をつぎの ように表すことができる。

$$
\begin{aligned}
& \dot{r}_{i}(t)=B_{i}\left(\theta_{i}(t)\right) G_{i} \Phi\left(\omega_{i}(t)\right) \\
& \dot{\theta}_{i}(t)=B_{\theta} G_{i} \Phi\left(\omega_{i}(t)\right)
\end{aligned}
$$

ただし，

$$
\begin{aligned}
B_{i}\left(\theta_{i}(t)\right) & =\left[\begin{array}{cc}
\cos \theta_{i}(t) & -d_{i, x} \sin \theta_{i}(t)-d_{i, y} \cos \theta_{i}(t) \\
\sin \theta_{i}(t) & d_{i, x} \cos \theta_{i}(t)-d_{i, y} \sin \theta_{i}(t)
\end{array}\right] \\
B_{\theta} & =\left[\begin{array}{ll}
0 & 1
\end{array}\right]
\end{aligned}
$$

である. $\operatorname{det} B_{i}\left(\theta_{i}(t)\right)=d_{i, x} \neq 0$ のとき, $B_{i}\left(\theta_{i}(t)\right)$ は常 に正則であることに注意する。

\section{2 線形化入力の生成}

各軸方向に対する速度入力を $\left(u_{i, x}(t), u_{i, y}(t)\right)$ とする とき, 仮想ビークルの位置に関する動特性 (4) 式に対す る線形化入力をつぎのように与える.

$$
\omega_{i}(t)=G_{i}^{-1} B_{i}\left(\theta_{i}(t)\right)^{-1} u_{i}(t)
$$

ただし,$u_{i}(t)=\left[u_{i, x}(t) u_{i, y}(t)\right]^{\top}$ とする.

移動ロボットの駆動源に対する入力 $\omega_{i}(t)$ が飽和に達 しなければ, 線形化入力 (6) 式によって仮想ビークルの 位置に関する動特性 (4) 式は積分器となる。しかし, 飽 和に達すれば積分器ではなくなる。すなわち, 動特性は

$$
\dot{r}_{i}(t)=B_{i}\left(\theta_{i}(t)\right) G_{i} \Phi\left(G_{i}^{-1} B_{i}\left(\theta_{i}(t)\right)^{-1} u_{i}(t)\right)
$$

となる，このことは，仮想ビークルに対する入力に飽和 を考慮すること,つまり，

$$
\dot{r}_{i}(t)=\Phi\left(u_{i}(t)\right)
$$

とは本質的に異なる 


\section{3 仮想ビークルに対する合意問題}

$N$ 台の移動ロボットがフォーメーションを形成するた めには, Fig. 2 のようにすべての移動ロボットに対応す る仮想ビークルがすべて一致すればよい. (4) 式および (6) 式から， $N$ 台の仮想ビークルの位置に関する動特性 および移動ロボットの駆動源に対する線形化入力をそれ ぞれつぎのように表す。

$$
\begin{aligned}
\dot{r}(t) & =B(\theta(t)) G \Phi(\omega(t)) \\
\omega(t) & =G^{-1} B(\theta(t))^{-1} u(t)
\end{aligned}
$$

ただし, $B(\theta(t))=$ blockdiag $\left[B_{1}\left(\theta_{1}(t)\right) \cdots B_{N}\left(\theta_{N}(t)\right)\right]$ $\in \mathbb{R}^{2 N \times 2 N}, G=$ blockdiag $\left[G_{1} \cdots G_{N}\right] \in \mathbb{R}^{2 N \times 2 N}, r(t)$ $=\left[r_{1}^{\top}(t), \ldots, r_{N}^{\top}(t)\right]^{\top} \in \mathbb{R}^{2 N}, \omega(t)=\left[\omega_{1}^{\top}(t), \ldots, \omega_{N}^{\top}(t)\right]^{\top} \in$ $\mathbb{R}^{2 N}, u(t)=\left[u_{1}^{\top}(t), \ldots, u_{N}^{\top}(t)\right]^{\top} \in \mathbb{R}^{2 N}$ とする. このと き,つぎの問題を考える.

【問題 1】 $r_{i}(t) \rightarrow r_{j}(t)(t \rightarrow \infty)$

【問題 2】 $\left(r_{i}(t), \theta_{i}(t)\right) \rightarrow\left(r_{j}(t), \theta_{j}(t)\right)(t \rightarrow \infty)$ どちらの問題においても, $i \neq j$ である. 問題 1 は位置の みの合意, 問題 2 は位置と姿勢角の合意に関する問題で ある。とくに，問題 2 はVS 合意問題とよばれる 87. す でに述べたように，仮想ビークルの位置と姿勢角が合意 していれば，移動ロボットはフォーメーションを形成す る。仮想ビークルの位置のみが合意しても，姿勢角の合 意がなければ移動ロボットの位置はフォーメーションを 形成しない [9].しかし，仮想ビークルが平面上で静止 する合意を得ると同時に姿勢角についても合意を得るこ とは困難である。一方，仮想ビークルが平面上を一定方 向に等速で移動する位置および姿勢角の合意を同時に得 ることは可能であり，このときに移動ロボットがフォー メーションを形成することができる [8].

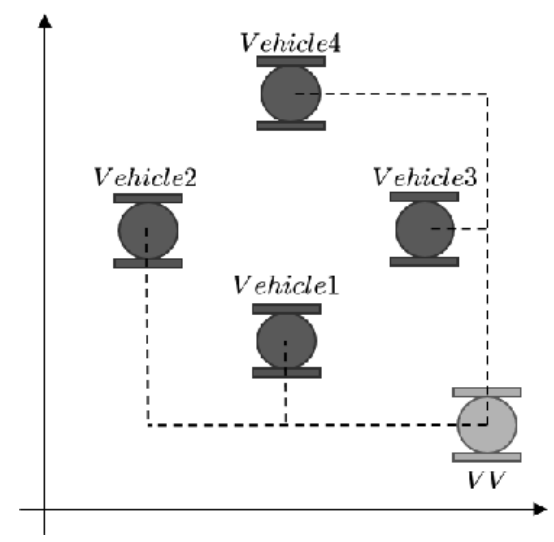

Fig. 2 Consensus of virtual vehicles

\section{3. フォーメーション制御}

移動ロボットの駆動源に飽和がある場合，一般的な合 意プロトコル $[1]$ を用いて VS 合意を得るのは困難であ る．ここでは，駆動源 $\omega_{i}(t)$ を飽和の上限および下限の 範囲に収めるような時変ゲインをプロトコルに導入する
ことを検討する。

\section{1 位置の合意}

移動ロボットの駆動源に対する入力 (6) 式に対し, つ ぎのプロトコルを考える.

$$
u_{i}(t)=-c_{i}(t) \sum_{j \in \mathcal{N}_{i}}\left(r_{i}(t)-r_{j}(t)\right)
$$

ここで, $c_{i}(t)$ は時変ゲインである. (8) 式および $(9)$ 式 から移動ロボットに加える入力は

$$
\omega(t)=\left(C(t) \otimes I_{2}\right) G^{-1} B(\theta(t))^{-1}\left(-\mathcal{L} \otimes I_{2}\right) r(t)
$$

となる。ただし， $C(t)=\operatorname{diag}\left[c_{1}(t), \ldots, c_{N}(t)\right]$ である. $c_{i}(t)$ に対して，つぎの仮定をおく.

（仮定 3）プロトコル (9) 式を線形化入力 (6) 式に 用いたとき，移動ロボットの駆動源 $\omega_{i}(t)$ が飽和しな いように $c_{i}(t)$ が調整される。ただし， $\underline{c}_{i}>0$ に対して $\underline{c}_{i}<c_{i}(t)<\infty$ とする.

仮定 3 のもとでは, (10) 式を入力として仮想ビークル $(7)$ 式に用いると飽和は存在しないことに等しくなるが，時 変なプロトコルを許す必要がある，このとき，仮想ビー クルの位置に関する動特性は

$$
\dot{r}(t)=\left(C(t) \otimes I_{2}\right)\left(-\mathcal{L} \otimes I_{2}\right) r(t)
$$

と表すことができる。いま， $\mathcal{L}=\mathcal{L}(G)$ の固有值 $\lambda_{i}$ を $\lambda_{1} \leq \cdots \leq \lambda_{N}$ となるようにとり, 対応する右固有べクト ル $x_{L r i}$ を $U_{R}=\left[x_{L r 1}, \ldots, x_{L r N}\right]$ とする. このとき, 仮想 ビークルの位置について，つぎの定理が成立する [9].

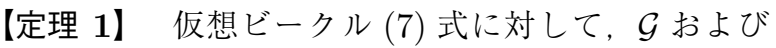
$\mathcal{L}(\mathcal{G})$ が仮定 1 および 2 を満たし，プロトコル $(9)$ 式のゲ イン $c_{i}(t)(i=1, \ldots, N)$ が仮定 3 を満たすとする。この とき，仮想ビークルの位置はつぎのように収束する.

$$
r(t) \rightarrow\left(U_{R} \otimes I_{2}\right)\left[\begin{array}{c}
\Xi_{1} \\
\Xi_{2} \\
0 \\
\vdots \\
0
\end{array}\right]=\frac{1}{\sqrt{N}}\left[\begin{array}{c}
\Xi_{1} \\
\Xi_{2} \\
\vdots \\
\Xi_{1} \\
\Xi_{2}
\end{array}\right](t \rightarrow \infty)
$$

ただし， $U_{R}$ は $\mathcal{L}(\mathcal{G})$ の右固有べクトルを各列にもつ直 交行列であり， $\Xi_{1}, \Xi_{2} \in \mathbb{R}$ は定数である.

（証明）付録 2.を参照せよ。

定理 1 は問題 1 の解を与えており, (9) 式は合意プロト コルである，標準的な合意プロトコルでは，ゲインを一 定 $\left(c_{i}(t)=c\right)$ とする [1]. 標準的な合意プロトコルですべ ての移動ロボットの駆動源が飽和しないようにするには, 移動ロボットの初期状態に応じてゲインを小さな定数に 設定する必要がある。移動ロボットごとに仮定 3 を満た す時変ゲイン $c_{i}(t)$ を設定できれば，駆動源が飽和して いない移動ロボットが小さいゲインの影響で低速化する ことを防ぐことができる。 


\section{2 位置および姿勢角の合意}

移動ロボットの駆動源に対する入力 (6) 式に対し, つ ぎのプロトコルを考える。

$$
u_{i}(t)=-c_{i}(t) \sum_{j \in \mathcal{N}_{i}}\left(r_{i}(t)-r_{j}(t)\right)+d \dot{r}_{d}
$$

ここで, $\quad \dot{r}_{d}=v_{d}\left[\cos \theta_{d} \sin \theta_{d}\right]^{\top}$ は移動ロボットの各軸 方向の一定の目標速度, $c_{i}(t)$ は時変ゲイン,$d>0$ は定 数ゲインである. (13) 式で $d=0$ とすれば $(9)$ 式となる. $\dot{r}_{d}$ はフォーメーションに対する参照值の役割を果たし， 移動ロボットの初期值に依存せずにフォーメーションを 形成しながら移動することを可能にする． $c_{i}(t)$ および $d$ に対して，つぎの仮定をおく.

（仮定 4）プロトコル (13) 式を線形化入力 (6) 式に用 いたとき，移動ロボットの駆動源 $\omega_{i}(t)$ が飽和しないよ うに $c_{i}(t)$ および $d$ が調整される。ただし， $\underline{c}_{i}>0$ に対し て $\underline{c}_{i}<c_{i}(t)<\infty$ とする.

仮定 4 のもとで，仮想ビークルの動特性は

$$
\begin{aligned}
& \dot{r}(t)=\left(C(t) \otimes I_{2}\right)\left(-\mathcal{L} \otimes I_{2}\right) r(t)+d\left(\mathbf{1}_{N} \otimes \dot{r}_{d}\right) \\
& \dot{\theta}(t)=-d v_{d} S(\theta(t))
\end{aligned}
$$

と表すことができる。ただし，

$$
S(\theta(t))=\left[\frac{\sin \left(\theta_{1}(t)-\theta_{d}\right)}{d_{1, x}}, \ldots, \frac{\sin \left(\theta_{N}(t)-\theta_{d}\right)}{d_{N, x}}\right]^{\top}
$$

である。

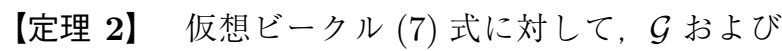
$\mathcal{L}(\mathcal{G})$ が仮定 1 および 2 を満たし，プロトコル $(13)$ 式の ゲイン $c_{i}(t)(i=1, \ldots, N)$ および $d$ が仮定 4 を満たすとす る。このとき，仮想ビークルの位置と姿勢角はつぎのよ うに収束する。

$$
\begin{aligned}
& r(t) \rightarrow \frac{1}{\sqrt{N}}\left[\begin{array}{c}
\Xi_{1} \\
\Xi_{2} \\
\vdots \\
\Xi_{1} \\
\Xi_{2}
\end{array}\right]+\left(\mathbf{1}_{N} \otimes \dot{r}_{d}\right) t \quad(t \rightarrow \infty) \\
& \theta(t) \rightarrow \theta_{d} \mathbf{1}_{N}(t \rightarrow \infty)
\end{aligned}
$$

ただし， $\Xi_{1}, \Xi_{2} \in \mathbb{R}$ は定数である.

（証明）付録 3.を参照せよ。

定理 2 は問題 2 の解を与えており，(13) 式は合意プロト コルである。

\section{4. ゲインの設計}

合意プロトコル $(13)$ 式における時変ゲイン $c_{i}(t)$ と定 数ゲイン $d$ が仮定 4 を満たすための条件について検討 する．合意プロトコル (13) 式を (6) 式に用いると，各移 動ロボットの駆動源への入力は

$$
\omega_{i}(t)=\Omega_{i 1}(t)+\Omega_{i 2}(t)
$$

と表すことができる。ただし，

$$
\begin{aligned}
& \Omega_{i 1}(t)=-c_{i}(t) G_{i}^{-1} B_{i}\left(\theta_{i}(t)\right)^{-1} \sum_{j \in \mathcal{N}_{i}}\left(r_{i}(t)-r_{j}(t)\right) \\
& \Omega_{i 2}(t)=d G_{i}^{-1} B_{i}\left(\theta_{i}(t)\right)^{-1} \dot{r}_{d}
\end{aligned}
$$

である。ここでは $\Omega_{i 1}(t)$ と $\Omega_{i 2}(t)$ がそれぞれ飽和しな い条件を考えることで， $\omega_{i}(t)$ が飽和しないようにする. すなわち, $\Omega_{i 1}(t)$ および $\Omega_{i 2}(t)$ が

$$
\Omega_{i 1}(t) \in\left(-\bar{v}_{s}, \bar{v}_{s}\right), \Omega_{i 2}(t) \in\left(-\bar{v}_{g}, \bar{v}_{g}\right)
$$

を満たす $c_{i}(t)$ および $d$ の条件を考える。ただし， $\bar{\omega}=$ $\bar{v}_{s}+\bar{v}_{g}$ とする，そのため，つぎの $c_{i}(t)$ および $d$ を導入 する。

$$
\begin{aligned}
c_{i}(t) & =\frac{\bar{v}_{s}}{\max _{i}\left\{\bar{v}_{s},\left|\omega_{i 1, R}(t)\right|,\left|\omega_{i 1, L}(t)\right|\right\}} \\
d & =\min _{i}\left\{\frac{\bar{v}_{g}}{\frac{T_{i}}{\left|d_{i, x}\right| R_{i}} \Gamma_{i} v_{d}\left(\cos \theta_{d}+\sin \theta_{d}\right)}\right\}
\end{aligned}
$$

ただし，

$$
\begin{aligned}
{\left[\begin{array}{l}
\omega_{i 1, R}(t) \\
\omega_{i 1, L}(t)
\end{array}\right] } & =G_{i}^{-1} B_{i}\left(\theta_{i}(t)\right)^{-1} \sum_{j \in \mathcal{N}_{i}}\left(r_{i}(t)-r_{j}(t)\right) \\
\Gamma_{i} & =\sqrt{\frac{d_{i, x}^{2}}{T_{i}}+\frac{d_{i, y}^{2}}{T_{i}}+\frac{\left|d_{i, y}\right|}{T_{i}}+\frac{1}{4}}
\end{aligned}
$$

である。このとき，つぎの補題が成立する.

【補題 1】時変ゲインおよび定数ゲインをそれぞれ (20) 式および (21) 式で与えるとき, 駆動源への入力 (18) 式において条件 (19) 式が満たされる.

（証明）付録 4.を参照せよ。

$\left|\omega_{i 1, R}(t)\right|$ あるいは $\left|\omega_{i 1, L}(t)\right|$ が与えられた $\bar{v}_{s} よ り 大$ きくなる時刻 $t$ では $(20)$ 式の $c_{i}(t)$ は 1 末満の值をとる. このような時刻が続く場合, $r_{i}(t)-r_{j}(t)$ が時刻の経過 にともない発散しない限り $c_{i}(t)$ が 0 に漸近することは ない.つまり, $t \geq 0$ において $\underline{c}_{i}<c(t) \leq 1(<\infty)$ を満た す $\underline{c}_{i}>0$ が存在する. したがって, フォーメーション形 成の前に移動ロボットが停止することはない.

\section{5. 数值例}

移動ロボット (1), (2) 式の台数を $N=4$ とし， ロボッ ト間の通信トポロジを表すグラフのグラフラプラシアン をつぎのように与える。

$$
\mathcal{L}=\left[\begin{array}{cccc}
1 & -1 & 0 & 0 \\
-1 & 2 & 0 & -1 \\
0 & 0 & 1 & -1 \\
0 & -1 & -1 & 2
\end{array}\right]
$$

これは，仮定 1 および 2 を満たす。また，(2) 式におい て, $\bar{\omega}_{i, R}=\bar{\omega}_{i, L}=\bar{\omega}=4 \pi, \quad R_{i}=0.026, \quad T_{i}=0.101$ とす 
る. 駆動源に対する入力 (6) 式に対し (13) 式の合意プロ トコルにおける時変ゲイン $c_{i}(t)$ を $(20)$ 式, 定数ゲイン $d$ を(21) 式とする. (19) 式においては $\bar{v}_{s}=\bar{v}_{g}=2 \pi$ とす る、ただし，いずれの場合も $v_{d}=0.1, \theta_{d}=\pi / 2$ とする.

移動ロボットと仮想ビークルの位置関係 $(3)$ 式について は, $d_{i}=\left[\begin{array}{ll}d_{i, x} & d_{i, y}\end{array}\right]$ として, $d_{1}=\left[\begin{array}{ll}0.3 & 0.3\end{array}\right], d_{2}=\left[\begin{array}{ll}0.3 & 0.6\end{array}\right]$, $d_{3}=\left[\begin{array}{ll}0.6 & 0.3\end{array}\right], d_{4}=\left[\begin{array}{ll}0.6 & 0.6\end{array}\right]$ とする．また，移動ロボッ 卜の初期状態を $r_{1}(0)=\left[\begin{array}{ll}-0.8 & 0.5\end{array}\right]^{\top}, r_{2}(0)=\left[\begin{array}{ll}0.9 & 0.5\end{array}\right]^{\top}$, $r_{3}(0)=\left[\begin{array}{ll}0.5 & -0.6\end{array}\right]^{\top}, \quad r_{4}(0)=\left[\begin{array}{ll}-0.9 & -0.5\end{array}\right]^{\top}, \quad \theta_{1}(0)=$ $-\pi / 3, \quad \theta_{2}(0)=-\pi / 5, \quad \theta_{3}(0)=-\pi / 4, \quad \theta_{4}(0)=-\pi$ とし たときの仮想ビークルの位置および姿勢角の時間応答を Fig. 3, 移動ロボットの駆動源に対する入力の時間応答を Fig. 4 にそれぞれ示す．仮想ビークルの位置および姿勢 角は合意しているので，移動ロボットはフォーメーショ ンを形成する，また，Fig. 4 より，移動ロボットへの実 入力が飽和していないこともわかる.
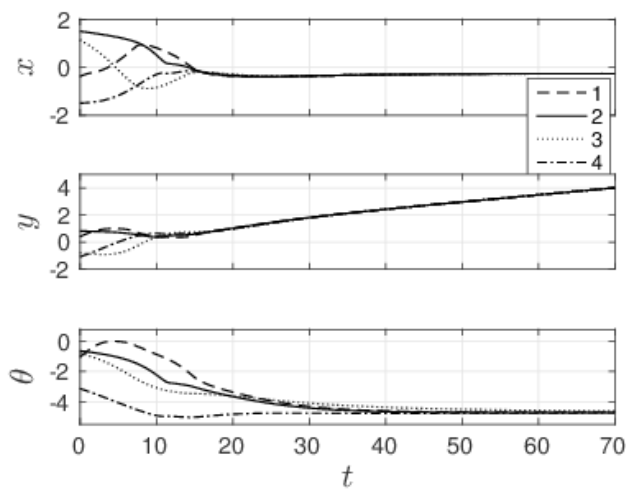

Fig. 3 Positions and angles of VVs (varying gain)
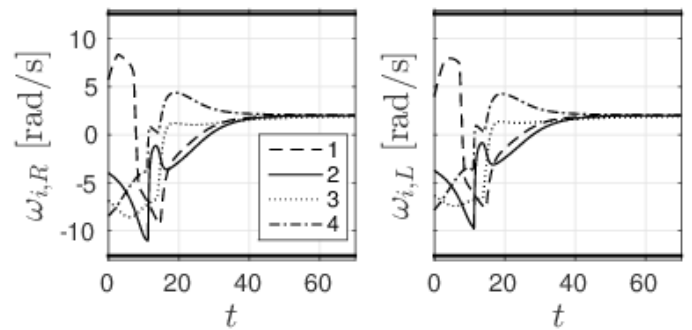

Fig. 4 Rotational speed of wheels (varying gain)

\section{6. 実験}

実験環境および使用した移動ロボットを Fig. 5 およ びFig. 6 にそれぞれ示す. 移動ロボットの位置および 姿勢角をモーションキャプチャにより観測する。観測し た位置および姿勢角に基づき制御入力 (6) 式を計算し, Xbeeの無線通信によって移動ロボットに送信する。た たし，移動ロボットに用いたモー夕の仕様上，低速域 で望ましい動作を得ることが難しいため, 左右の車輪 の入力角速度に定数值を加算する。.つまり，(6) 式にお ける $\omega_{i}(t)$ に対し, 新しい左右のモー夕の入力角速度を $\hat{\omega}_{i}(t)=\left[\hat{\omega}_{i, R}(t) \hat{\omega}_{i, L}(t)\right]^{\top}$ とする. ただし,

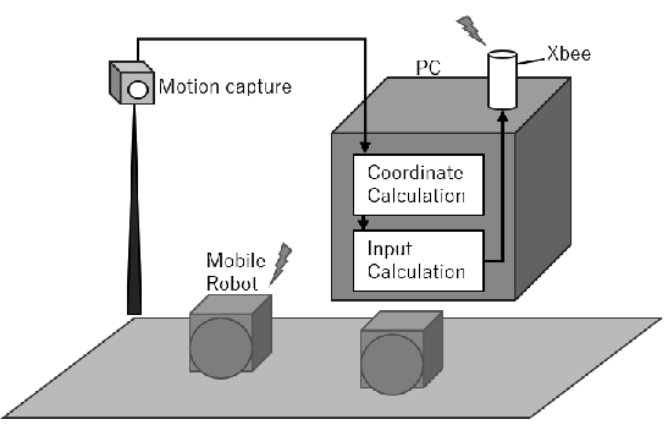

Fig. 5 Experimental environment

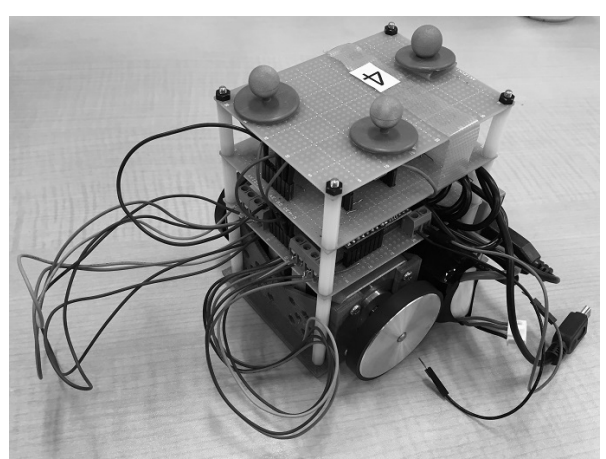

Fig. 6 Mobile robot

$$
\begin{aligned}
& \hat{\omega}_{i, R}(t)=\omega_{i, R}(t)+\frac{\pi}{4} \cdot \operatorname{sign}\left(\omega_{i, R}(t)\right) \\
& \hat{\omega}_{i, L}(t)=\omega_{i, L}(t)+\frac{\pi}{4} \cdot \operatorname{sign}\left(\omega_{i, L}(t)\right)
\end{aligned}
$$

とした。また、サンプリング周波数を $50[\mathrm{~Hz}]$ とした。 こ の点以外の設計は 5 .にしたがう.

移動ロボットの初期状態を $r_{1}(0)=[-0.08-0.26]^{\top}$, $r_{2}(0)=[0.33-0.60]^{\top}, r_{3}(0)=[-0.31-0.53]^{\top}, r_{4}(0)=$ $[0.63-0.44]^{\top}, \theta_{1}(0)=1.94, \theta_{2}(0)=2.42, \theta_{3}(0)=0.83$, $\theta_{4}(0)=0.92$ とする. 駆動源に対する入力 $(6)$ 式に対し, (13) 式の合意プロトコルにおけるゲイン $c_{i}(t), d$ をつ ぎのように選びそれぞれの場合について実験を行う.

i) $c_{i}(t)=1$ および $d=1$ とする $[1]$.

ii) $c_{i}(t)$ を $(20)$ 式, $d$ を $(21)$ 式とする.

i)の場合の仮想ビークルの位置および姿勢角の時間応 答を Fig. 7, 移動ロボットの軌跡を Fig. 8 にそれぞれ示 す.図から, 移動ロボットは高速で移動するものの, 仮 想ビークルの位置と姿勢角はいずれも合意しないことが わかる。一方で, ii)の場合の実機を用いた実験による仮 想ビークルの位置および姿勢角の時間応答を Fig. 9, 移 動ロボットの軌跡を Fig. 10 にそれぞれ示す. 図から, 設 計した制御入力により，仮想ビークルは合意を得ること がわかる，このとき，すべての移動ロボットは，高速で 無理な移動をすることなくフォーメーションを形成した.

\section{7. おわりに}

本論文では, 独立二輪駆動の移動ロボットに対し, 駆 動源の飽和を考慮した合意問題について考えた。仮想構 造を用いたVS 合意のために制御入力を分割し，時変ゲ 

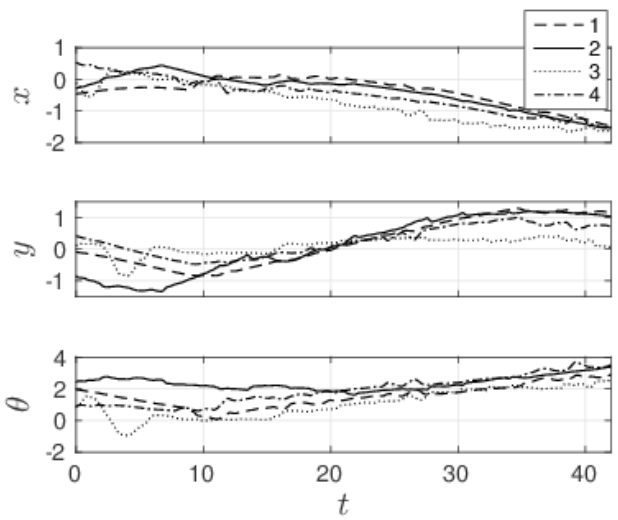

Fig. 7 Positions and angles of VVs (Condition (i))

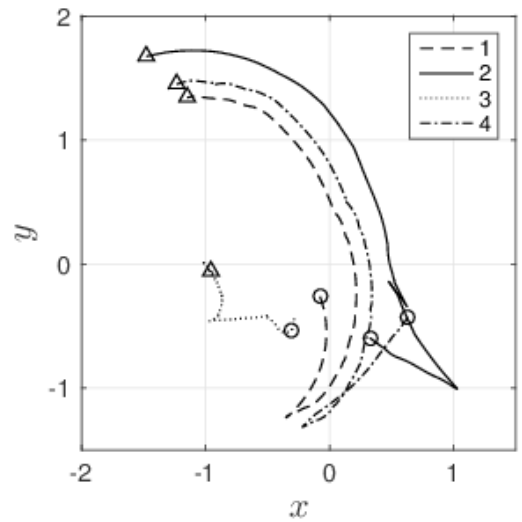

Fig. 8 Trajectories of mobile robots (Condition (i))
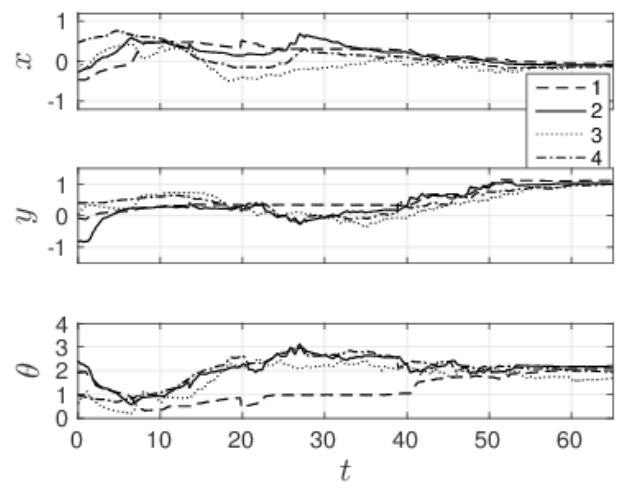

Fig. 9 Positions and angles of VVs (Condition(ii))

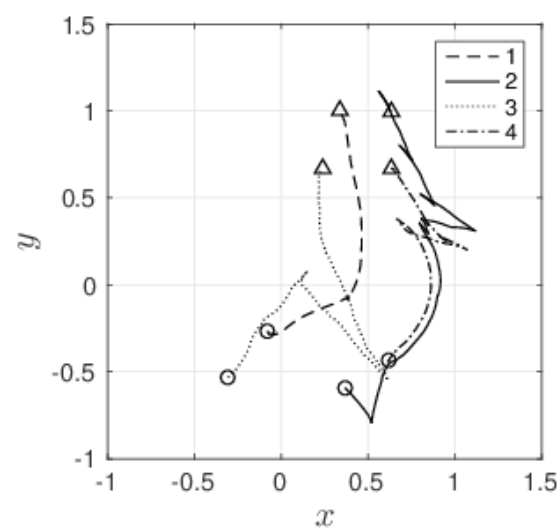

Fig. 10 Trajectories of mobile robots (Condition(ii))
インと定数ゲインを導入した。これらを用いた制御則に より，実入力が飽和することを防ぎつつ速応性の高い合 意制御を実現した。 また，この制御則に用いる時変ゲイ ンと定数ゲインの一つの設計法を提案し, 数值計算と実 機実験によって，その有効性を確認した.

本研究は JSPS 科研費 26420429 の助成を受けたもの です。実機実験においては，中井優希君，三雲隆平君に 手伝いをいただきました。また，貴重なコメントをいた だいた査読者のみなさまに感謝いたします。

\section{参 考文 献}

[1] R. Olfati-saber and R. M. Murray: Consensus problems in networks of agents with switching topology and time-delays; IEEE Trans. Autom. Control, Vol. 49, No. 9, pp. 1520-1532 (2004)

[2] R. Olfati-saber, J. A. Fax and R. M. Murray: Consensus and cooperation in networked multi-agent systems; Proc. IEEE, Vol. 95, No. 1, pp. 215-233 (2007)

[3] 東, 永原, 石井, 林, 桜間, 畑中: マルチエージェント システムの制御, コロナ社 (2015)

[4] M. Mesbahi and M. Egerstedt: Graph Theoretic Methods in Multiagent Networks, Princeton (2010)

[5] Y. Lin, J. Xiang and W. Wei: Consensus problems for linear time-invariant multi-agent systems with saturation constraints; IET Control Theory \& Applications, Vol. 5, No. 6, pp. 823-829 (2011)

[6] K. Takaba: Local synchronization of linear multiagent systems subject to input saturation; SICE Journal of Control, Measurement, and System Integration, Vol. 8, No.5, pp. 334-340 (2015)

[7] T. Ikeda, J. Jongusuk, T. Ikeda and T. Mita: Formation control of multiple nonholonomic mobile robots; Electrical Engineering in Japan, Vol. 157, No. 3, pp. 81-87 (2006)

[8] 吉川, 滑川: 仮想構造を用いたマルチビークルシステ ムのフォーメーション制御; 第 7 回制御部門大会予稿集 (2007)

[9] 中野, 市原: 駆動源に飽和を有する移動ロボットの合意 制御; 第 60 回システム制御情報学会研究発表講演会講演 論文集 $(2016)$

[10] D. S. Watkins: Fundamentals of Matrix Computations, 2nd Edition, Wiley (2004)

[11] 木村, 森, 藤井: ロバスト制御, コロナ社 (1994)

[12] R. A. Horn and C. R. Johnson: Matrix Analysis: Second Edition, Cambridge University Press (2013)

付 録

付録 1. 定理 1 の証明に必要となる定義および補題 つぎの線形時変システム

$$
\dot{x}=A(c(t)) x(t)
$$

について考える. ここで, $x \in \mathbb{R}^{n}$ は状態変数, $c(t) \in \mathcal{R} \subset$ $\mathbb{R}^{p}$ は時変パラメータ, $\mathcal{R}$ は $\mathbb{R}^{p}$ の有界閉集合である. 
【定義 1】 [11] システム $(\mathrm{A} 1)$ に対して, 適当な $n$ 次正定対称行列 $P \succ 0$ と定数 $\alpha>0$ が存在し, 軌道 $x(t)$ に沿った二次形式 $V(x(t))=x(t)^{\top} P x(t)$ の時間微分が $c(t)$ と無関倸に

$$
\begin{aligned}
\dot{V}(x(t)) & =x(t)^{\top}\left[A(c(t))^{\top} P+P A(c(t))\right] x(t) \\
& \leq-\alpha\|x(t)\|^{2}
\end{aligned}
$$

を満たすとき，システム $(\mathrm{A} 1)$ は二次安定であるという.

【補題 2】 [11] システム $(\mathrm{A} 1)$ が二次安定であると き, 平衡点 $x=0$ は時変パラメー夕 $c(t)$ のもとで大域的 一様指数安定である.

【補題 3】（[12], p.242）Ａおよび $B$ が $n$ 次実対称 行列であり， $B$ が正定対称行列であるとき， $A$ の $i$ 番目 に小さな固有值 $\lambda_{i}(A)$ と $A+B$ の $i$ 番目に小さな固有值 $\lambda_{i}(A+B)$ について，つぎの関係が成立する。

$$
\lambda_{i}(A)<\lambda_{i}(A+B) \quad(i=1, \ldots, n)
$$

【定義 2】 ([12], p.477) $A=\left[a_{i j}\right] \in \mathbb{R}^{m \times n}$ および $B=\left[b_{i j}\right] \in \mathbb{R}^{m \times n}$ に対して,$A \circ B=\left[a_{i j} b_{i j}\right] \in \mathbb{R}^{m \times n}$ を シュール積（アダマール積）という。

【補題 4】（[12], p.479) $A$ が $n$ 次正定対称行列で あり, $B$ が $n$ 次半正定対称行列かつ正の主対角成分をも つとき，行列のシュール積 $A \circ B$ は正定対称行列である.

【補題 5】 $A$ を $n$ 次の正定対称行列, $B$ を $n$ 次の正定 対角行列とする。このとき， $A B+B A \succ 0$ が成立する.

(証明） $B$ の対角成分を $b_{i i}(i=1, \ldots, n)$ とすると，

$$
A B+B A=\Delta \circ A
$$

と表現できる。ただし，

$$
\Delta=\left[\begin{array}{cccc}
b_{11} & b_{22} & \cdots & b_{n n} \\
b_{11} & b_{22} & \cdots & b_{n n} \\
\vdots & \vdots & \ddots & \vdots \\
b_{11} & b_{22} & \cdots & b_{n n}
\end{array}\right]+\left[\begin{array}{cccc}
b_{11} & b_{11} & \cdots & b_{11} \\
b_{22} & b_{22} & \cdots & b_{22} \\
\vdots & \vdots & \ddots & \vdots \\
b_{n n} & b_{n n} & \cdots & b_{n n}
\end{array}\right]
$$

である. (A2) 式の右辺は重複度 $n-1$ の固有值 0 と重複 度 1 の固有值 $\sum_{i=1}^{n} b_{i i}$ をもつ行列とその転置の和である から, $\Delta$ は半正定対称行列である. よって, 補題 4 より $A B+B A \succ 0$ となる.

\section{付録 2. 定理 1 の証明}

仮定 1 から $\mathcal{L}=\mathcal{L}(\mathcal{G})$ は対称行列であるため, 固有值 は実数であり固有べクトルを実べクトルに選ぶことがで きる. さらに，仮定 2 から $\mathcal{L}$ の固有值 $\lambda_{i}$ と対応する右 固有ベクトルを $x_{L r i}$ を $0=\lambda_{1}<\lambda_{2} \leq \cdots \leq \lambda_{N}$ および

$$
\mathcal{L} U_{R}=U_{R} \Lambda
$$

となるようにできる.ここで, $U_{R}=\left[x_{L r 1}, \ldots, x_{L r N}\right]$ は 直交行列， $\Lambda=\operatorname{diag}\left[\lambda_{1}, \lambda_{2}, \ldots, \lambda_{N}\right]$ は対角行列である. いま, $\xi(t)=\left(U_{R}^{\top} \otimes I_{2}\right) r(t)$ とする. 両辺を微分し (11) 式を用いると，

$$
\dot{\xi}(t)=\left(-Q(t) \otimes I_{2}\right) \xi(t)
$$

を得る。ただし， $Q(t)=U_{R}^{\top} C(t) U_{R} \Lambda$ であり，

$$
\begin{aligned}
& \left(U_{R}^{\top} \otimes I_{2}\right)\left(C(t) \otimes I_{2}\right)\left(-\mathcal{L} \otimes I_{2}\right) r(t) \\
= & \left(U_{R}^{\top} \otimes I_{2}\right)\left(C(t) \otimes I_{2}\right)\left(-\mathcal{L} \otimes I_{2}\right)\left(U_{R} \otimes I_{2}\right) \xi(t) \\
= & \left(-\left(U_{R}^{\top} C(t) U_{R} \Lambda\right) \otimes I_{2}\right) \xi(t)
\end{aligned}
$$

を用いた． $Q(t)=\left[Q_{i, j}(t)\right]$ と表すとき $Q_{1,1}(t)=0$ であ る.さらに,

$$
\lim _{t \rightarrow \infty} \xi_{i}(t)=0 \quad(i=3, \ldots, 2 N)
$$

を満たすならば,

$$
\lim _{t \rightarrow \infty} \dot{\xi}_{i}(t)=0 \quad(i=1,2)
$$

となる。また， $\lambda_{1}=0$ に対応する固有ベクトルは $x_{L r 1}=$ $\mathbf{1}_{N} / \sqrt{N}$ と書くことができるので, $r(t)=\left(U_{R} \otimes I_{2}\right) \xi(t)$ であることから (12) 式が成立し合意を得ることができ る. $U_{R}$ は実行列であるので $\Xi_{1}$ および $\Xi_{2}$ は実定数とな る。以下では, (A5) 式を示す。

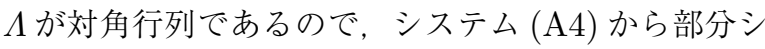
ステム

$$
\dot{\zeta}(t)=\left(-\hat{Q}(t) \otimes I_{2}\right) \zeta(t)
$$

を考えることができる．ただし， $\zeta(t)=\left[\xi_{3}(t), \ldots, \xi_{2 N}(t)\right]^{\top}$ $\in \mathbb{R}^{2(N-1)}$ は部分システムの状態, $\hat{Q}(t) \in \mathbb{R}^{N-1 \times N-1}$ は $Q(t)$ の第 1 行目と第 1 列目を取り除いた行列であ る。 システム $(\mathrm{A} 6)$ に対して, Lyapunov 関数の候補を $V(\zeta(t))=\zeta(t)^{\top} P \zeta(t)$ とおく. ただし，

$$
P=p \cdot I_{N-1} \otimes I_{2}, \quad p>0
$$

である．Pは正定対角行列であるので, $V(\zeta(t))$ は正定 值である。このとき, $V(\zeta(t))$ の時間微分はつぎのよう になる。

$$
\dot{V}(\zeta(t))=-\zeta(t)^{\top}\left(P\left(\hat{Q}(t) \otimes I_{2}\right)+\left(\hat{Q}(t) \otimes I_{2}\right)^{\top} P\right) \zeta(t)
$$

一方, $Q(t)=U_{R}^{\top} C(t) U_{R} \Lambda$ において, $U_{R}^{\top} C(t) U_{R}$ から 第 1 行目と第 1 列目を除いた行列を $R(t), \Lambda$ から第 1 行 目と第1列目を取り除いた行列を $\hat{\Lambda}$ とすと， $\lambda_{1}=0 て ゙$ あることから，

$$
\hat{Q}(t)=R(t) \hat{\Lambda}
$$

と表すことができる，ここで， $\hat{Q}(t)$ は対称行列ではない ことに注意する。

つぎに, $R(t) \succ 0$ を示す. $U_{R}$ から第 1 行目と第 1 列 目を除いた行列を $\hat{U}_{R}$ とし, $C(t)$ から第 1 行目と第 1 列 目を除いた行列を $\hat{C}(t)=\operatorname{diag}\left[c_{2}(t), \ldots, c_{N}(t)\right]$ とすると，

$$
R(t)=\hat{U}_{R}^{\top}\left(\hat{C}(t)-c_{1}(t) \cdot I_{N-1}\right) \hat{U}_{R}+c_{1}(t) \cdot I_{N-1}
$$




$$
=\hat{U}_{R}^{\top} \hat{C}(t) \hat{U}_{R}+c_{1}(t)\left(I_{N-1}-\hat{U}_{R}^{\top} \hat{U}_{R}\right)
$$

となる。 ここで, 仮定 3 より， $\hat{C}(t)$ は正定対角行列であ る.また, $U_{R}^{\top} U_{R}=I$ であるので, $I-\hat{U}_{R}^{\top} \hat{U}_{R}$ は

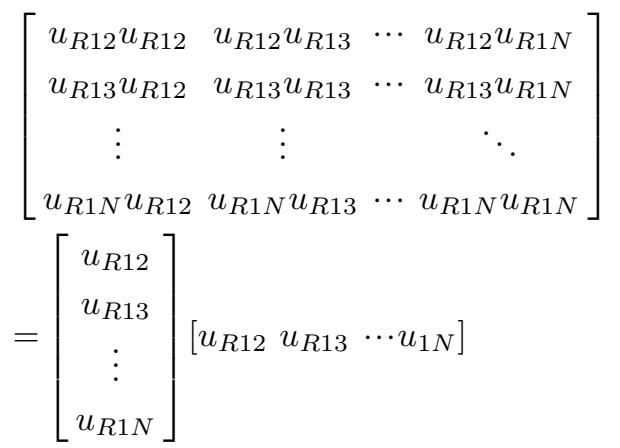

と書き表すことができる。つまり，I- $\hat{U}_{R}^{\top} \hat{U}_{R}$ は重複度 $N-2$ の固有值 0 と重複度 1 の固有值 $u_{R 12}^{2}+u_{R 13}^{2}+\cdots+$ $u_{R 1 N}^{2}>0$ をもつ, 半正定対称行列である. したがって, 補題 3 より $R(t) \succ 0$ を得る.

最後に，(A5) 式を示す， $\hat{\Lambda}$ が正定対角行列であり $R(t) \succ 0$ であるので, 補題 $\mathbf{5}$ より $\hat{Q}(t)+\hat{Q}(t)^{\top}=R(t) \hat{\Lambda}+$ $(R(t) \hat{\Lambda})^{\top}=R(t) \hat{\Lambda}+\hat{\Lambda} R(t) \succ 0$ である. さらに, $P \succ 0$ であることから, 補題 $\mathbf{5}$ を再度用いることで, $P(\hat{Q}(t) \otimes$ $\left.I_{2}\right)+\left(\hat{Q}(t) \otimes I_{2}\right)^{\top} P \succ 0$ を得る。このとき，

$$
P\left(\hat{Q}(t) \otimes I_{2}\right)+\left(\hat{Q}(t) \otimes I_{2}\right)^{\top} P \succeq \alpha I
$$

を満たす定数 $\alpha>0$ が存在する。兄に，(A7) 式から

$$
\dot{V}(\zeta(t)) \leq-\alpha\|\zeta(t)\|^{2}
$$

となる. 時変パラメータを $c(t)=\left[c_{1}(t), \ldots, c_{N}(t)\right]^{\top} \in \mathbb{R}^{N}$ とするとき, 補題 2 よりシステム $(\mathrm{A} 6)$ の $\zeta(t)=0$ は大 域的一様指数安定である。したがって，(A5) 式が成立 する。

\section{付録 3．定理 2 の証明}

まず，位置について考えるため，偏差 $e(t)=r(t)-$ $d\left(\mathbf{1}_{N} \otimes \dot{r}_{d}\right) t$ を定義する。(14) 式を用いれば,

$$
\begin{aligned}
\dot{e}(t) & =\dot{r}(t)-d\left(\mathbf{1}_{N} \otimes \dot{r}_{d}\right) \\
& =\left(C(t) \otimes I_{2}\right)\left(-\mathcal{L} \otimes I_{2}\right) r(t) \\
& =\left(C(t) \otimes I_{2}\right)\left(-\mathcal{L} \otimes I_{2}\right)\left(e(t)+d\left(\mathbf{1}_{N} \otimes \dot{r}_{d}\right) t\right)
\end{aligned}
$$

となる．ここで， $\mathbf{1}_{N}$ が $\mathcal{L} の$ 零固有值に対応する右固有 ベクトルであることを考慮すれば

$$
\left(-\mathcal{L} \otimes I_{2}\right) d\left(\mathbf{1}_{N} \otimes \dot{r}_{d}\right) t=d\left(\left(\mathcal{L} \mathbf{1}_{N}\right) \otimes \dot{r}_{d}\right) t=\mathbf{0}_{2 N}
$$

であるから，

$$
\dot{e}(t)=\left(C(t) \otimes I_{2}\right)\left(-\mathcal{L} \otimes I_{2}\right) e(t)
$$

となる。このとき, 定理 1 から，偏差に関するシステ ムが合意することがわかる。したがって, $r(t)$ の収束は (16)式にしたがう.
つぎに，姿勢角について考える，(5)式，(6)式，(13) 式から，仮定 4 のもとでは

$$
\begin{aligned}
\dot{\theta}_{i}(t) & =B_{\theta} B_{i}\left(\theta_{i}(t)\right)^{-1} u_{i}(t) \\
& =B_{\theta} B_{i}\left(\theta_{i}(t)\right)^{-1}\left(-c_{i}(t) \sum_{j \in \mathcal{N}_{i}}\left(r_{i}(t)-r_{j}(t)\right)+d \dot{r}_{d}\right)
\end{aligned}
$$

である. $r(t)$ の収束は $r_{i}(t) \rightarrow r_{j}(t)$ を意味するので,

$$
\dot{\theta}_{i}(t)=B_{\theta} B_{i}\left(\theta_{i}(t)\right)^{-1} d \dot{r}_{d}=-\frac{d v_{d}}{d_{i, x}} \sin \left(\theta_{i}(t)-\theta_{d}\right)
$$

となる.したがって, $v_{d} \neq 0, d_{i, x} \neq 0$ のとき, $\theta(t)$ の収 束は(17)式にしたがう.

\section{付録 4. 補題 1 の証明}

時変ゲイン $(20)$ 式の值は, $\omega_{i 1, R}(t)$ および $\omega_{i 1, L}(t)$ が とる值の範囲によって，つぎのように分類できる.

$$
\left\{\begin{aligned}
c_{i}(t)=1: & \left(\omega_{i 1, R}(t), \omega_{i 1, L}(t) \in\left(-\bar{v}_{s}, \bar{v}_{s}\right)\right) \\
c_{i}(t)<1: & \left(\omega_{i 1, R}(t) \in\left(-\bar{v}_{s}, \bar{v}_{s}\right), \omega_{i 1, L}(t) \notin\left(-\bar{v}_{s}, \bar{v}_{s}\right)\right) \\
& \left(\omega_{i 1, R}(t) \notin\left(-\bar{v}_{s}, \bar{v}_{s}\right), \omega_{i 1, L}(t) \in\left(-\bar{v}_{s}, \bar{v}_{s}\right)\right) \\
& \left(\omega_{i 1, R}(t), \omega_{i 1, L}(t) \notin\left(-\bar{v}_{s}, \bar{v}_{s}\right)\right)
\end{aligned}\right.
$$

したがって，(20)式のように $c_{i}(t)$ を選ぶとき，いずれ の場合も $c_{i}(t) \leq \bar{v}_{s}$ となるので, $\Omega_{i 1}(t) \in\left(-\bar{v}_{s}, \bar{v}_{s}\right)$ を満 たす。

定数ゲイン $(21)$ 式の効果を調べるため, $G_{i}^{-1} B_{i}\left(\theta_{i}(t)\right)^{-1} \dot{r}_{d}$ をつぎのように表す。

$$
G_{i}^{-1} B_{i}\left(\theta_{i}(t)\right)^{-1} \dot{r}_{d}=\frac{T_{i} v_{d}}{d_{i, x} R_{i}}\left[\begin{array}{ll}
\mu_{i 1}(t) & \mu_{i 3}(t) \\
\mu_{i 2}(t) & \mu_{i 4}(t)
\end{array}\right]\left[\begin{array}{c}
\cos \theta_{d} \\
\sin \theta_{d}
\end{array}\right]
$$
ただし，

$$
\begin{aligned}
& \mu_{i 1}(t)=\frac{d_{i, x}}{T_{i}} \cos \theta_{i}(t)-\left(\frac{d_{i, y}}{T_{i}}+\frac{1}{2}\right) \sin \theta_{i}(t) \\
& \mu_{i 2}(t)=\frac{d_{i, x}}{T_{i}} \sin \theta_{i}(t)+\left(\frac{d_{i, y}}{T_{i}}+\frac{1}{2}\right) \cos \theta_{i}(t) \\
& \mu_{i 3}(t)=\frac{d_{i, x}}{T_{i}} \cos \theta_{i}(t)-\left(\frac{d_{i, y}}{T_{i}}-\frac{1}{2}\right) \sin \theta_{i}(t) \\
& \mu_{i 4}(t)=\frac{d_{i, x}}{T_{i}} \sin \theta_{i}(t)+\left(\frac{d_{i, y}}{T_{i}}-\frac{1}{2}\right) \cos \theta_{i}(t)
\end{aligned}
$$

である。ここで， $a, b \in \mathbb{R}$ に対して $a \cos \theta_{i}+b \sin \theta_{i}=$ $\sqrt{a^{2}+b^{2}} \sin \left(\theta_{i}+\phi_{i}\right)$ と整理できることに注意する。た だし， $\phi_{i}=\tan ^{-1}(a / b)$ である。このとき，

$$
\left|\mu_{i j}(t)\right| \leq \Gamma_{i} \quad(j=1, \ldots, 4)
$$

と表すことができる。したがって， $G_{i} B_{i}\left(\theta_{i}(t)\right)^{-1} \dot{r}_{d}$ の 各成分の絶対值は,

$$
\frac{T_{i}}{\left|d_{i, x}\right| R_{i}} \Gamma_{i} v_{d}\left(\cos \theta_{d}+\sin \theta_{d}\right)
$$

を超えることはない．したがって，(21) 式のようにdを 選ぶとき， $\Omega_{i 2}(t) \in\left(-\bar{v}_{g}, \bar{v}_{g}\right)$ を満たす。 


\section{著者略歴}

等望裕虫 (正会員)

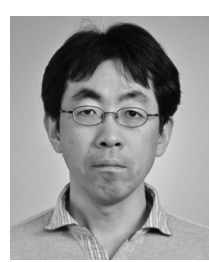

2000 年 3 月明治大学大学院理工学研究 科機械工学専攻博士後期課程修了. 同年 4 月明治大学理工学部助手, 2001 年 7 月茨 城大学大学院理工学研究科 SVBL 非常勤 研究員, 2002 年 4 月九州工業大学情報工 学部助手, 2010 年 4 月明治大学理工学部 中势野竟平 (正会員)

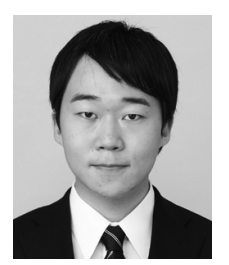

2015 年 3 月明治大学理工学部機械情報 工学科卒業, 2017 年 3 月同大学大学院理工 学研究科機械工学専攻博士前期課程修了. 2017 年本会奨励賞受賞. 移動ロボットの 制御に興味をもつ。 4 月から 1 年間 LAAS-CNRS (フランス) 客員研究員 制御 工学の研究に従事. 博士 (工学). 計測自動制御学会. IEEE の会員. 